\title{
Digoxin toxicity: crucial to diagnose
}

\author{
Tejas A. Acharya ${ }^{a}{ }^{*}$, Dimple S. Mehta ${ }^{a}$, Ritesh S. Vekariya ${ }^{b}$
}

a Department of Pharmacology, C.U. Shah Medical College and Hospital, Surendranagar 363001, India, ${ }^{\mathrm{b}}$ Department of Medicine, C.U. Shah Medical College and Hospital, Surendranagar 363001, India

Received: 7 August 2012

Accepted: 9 August 2012

*Correspondence to:

Dr. Tejas A. Acharya,

Email: drtejasacharya@gmail.com

\begin{abstract}
Digoxin is mainly used for heart failure and arrhythmias like atrial flutter and fibrillation. Digoxin is like double edged sword because of its potency to cause life threatening complications like various arrhythmias. Furthermore, it is difficult and important to recognize cardio toxicity caused by digoxin to prevent threat to life. We report a case which was initially diagnosed as arrhythmia and later turned as digoxin toxicity.
\end{abstract}

Keywords: Cardiac glycoside, Arrhythmia, Congestive heart failure

orally. While examination, in OPD suddenly patient became unconscious. Patient was admitted to medicine ICU. On examination his pulse was $100 / \mathrm{min}$ and blood pressure was $100 / 90 \mathrm{~mm}$ of $\mathrm{Hg}$. On ECG he was diagnosed as having ventricular tachycardia.

After initial diagnosis of ventricular tachycardia emergency management was done with $\mathrm{O}_{2}$ inhalation (2 lit/min), DC shock (200 J) and amiodarone (150mg IV over $10 \mathrm{~min}$ followed by $3.3 \mathrm{ml} /$ hour after diluting with $50 \mathrm{ml}$ normal saline). Rest of the treatment was continued as patient was receiving for 2.5 months. Patient became conscious after emergency management. Laboratory analysis was done including routine blood reports, serum creatinine and electrolytes, blood sugar and urine routine report. All the parameters were within normal limit. After 4 hours, patient's condition started deteriorating and pulse fell down to $30 / \mathrm{min}$. In spite of proper management deteriorating condition aroused suspicion of digoxin induced ventricular tachycardia and serum digoxin level was advised on second day. Treatment modification was done by stopping amiodarone infusion and administration of atropine (1 mg IV stat). On third day, serum digoxin level suggested high level with value of $2.88 \mathrm{ng} / \mathrm{ml}$, which was considerably high to cause toxicity. Digoxin introduction was stopped immediately and patient was monitored for general condition. After 24 hour of close observation, on fourth day; patient's pulse rate improved to $64 / \mathrm{min}$ with $108 / 60 \mathrm{~mm}$ of $\mathrm{Hg}$ blood pressure. Patient's general condition was improved with minor complain of constipation, which was treated with syrup lactulose (15 ml HS). This adverse drug reaction was reported by pharmacovigilance centre of our tertiary care 
centre and WHO causality ${ }^{5}$ assessment was done, which categorized it as certain event. Patient was observed for next four days with outcome of stabilized pulse rate of 64/min and 130/90 $\mathrm{mm}$ of $\mathrm{Hg}$ blood pressure with relieved ventricular tachycardia. Patient was discharged with advice of oral treatment with combination of aspirin, atorvastatin and glycine $(75 \mathrm{mg}, 10 \mathrm{mg}$ and $37.5 \mathrm{mg}$ OD respectively), losartan (50mg OD), combination of torsamide and spironolactone (25 $\mathrm{mg}$ and $40 \mathrm{mg}$ OD respectively), amiodarone (200 $\mathrm{mg}$ OD) and syrup lactulose (15 ml HS). After 7 days on follow up, patient's condition was better with all parameters within normal range.

\section{DISCUSSION}

Digoxin usage has decreased in the treatment of congestive heart failure and atrial fibrillation as a result of its inferiority to beta-adrenergic inhibitors and agents that interfere with the deleterious effects of the activated renin-angiotensin-aldosterone system. ${ }^{6}$ As use of digoxin has decreased and when it is used usually at lower dose adverse effects has become lower but it is often overlooked whenever it occurs. Factors responsible for toxicity are older age, female sex, low lean body mass, and renal insufficiency. In present case patient was initially treated as arrhythmia and DC shock was given but DC shock is contraindicated in patients with high serum digoxin level, as it can lead to ventricular fibrillation and may be fatal for patient. $^{7}$ Furthermore amiodarone was introduced for ventricular tachycardia but it can cause fatal interaction with digoxin if serum digoxin level is already high. ${ }^{8}$ It clearly indicates how crucial is to diagnose digoxin toxicity and manage it properly.

\section{REFERENCES}

1. Hollman A. Digoxin comes from Digitalis lanata. BMJ. 1996; 312:912.

2. Tripathi KD. Cardiac glycosides and drugs for heart failure. Essentials of medical pharmacology. $6^{\text {th }}$ ed. New Delhi: Jaypee Brothers; 2009:493-507.

3. Zand F, Asadi S, Katibeh P. Good Outcome after Digoxin Toxicity Despite Very High Serum Potassium Level. Iran Red Crescent Med J 2011; 13: 680-1.

4. Doering W, Konig E, Sturm W. Digitalis intoxication: specifity and significance of cardiac and extracardiac symptoms. part I: Patients with digitalis-induced arrhythmias. Z Kardiol 1977; 66: 121-8.

5. The Uppsala monitoring centre. The use of WHOUMC system for standardised case causality assessment. Available at http://www.who-umc.org. Accessed 1 August 2012.

6. Yang EH, Shah S, Criley JM. Digitalis toxicity: a fading but crucial complication to recognize. Am $\mathbf{J}$ Med 2012; 125:337-43.
7. Maron BA, Rocco TP. Pharmacotherapy of congestive heart failure. In: Bruton LS, editor. Goodman \& Gillman's The Pharmacological basis of Therapeutics. $12^{\text {th }}$ ed. USA: Mc Graw Hill publication; 2011:789-813.

8. Lexi-Comp Online ${ }^{\mathrm{TM}}$ Interaction Lookup, 2010. Available at http://www.uptodate.com/crlsql/interact/frameset.jsp . Accessed 1 August 2012. 